\title{
CHANGES IN THE ELECTRICAL PROPERTIES OF OLFACTORY EPITHELIAL CELLS IN THE TIGER SALAMANDER AFTER OLFACTORY NERVE TRANSECTION ${ }^{1}$
}

\author{
LEONA M. MASUKAWA, BRITTA HEDLUND, ${ }^{2}$ AND GORDON M. SHEPHERD \\ Section of Neuroanatomy, Yale University, School of Medicine, New Haven, Connecticut 06510
}

Received March 29, 1984; Revised July 20, 1984; Accepted July 25, 1984

\begin{abstract}
Transection of olfactory nerves causes degeneration of receptor neurons in the olfactory epithelium, followed by generation of new receptor neurons. We have carried out intracellular recordings to document changes in epithelial cell populations during receptor neuron degeneration and regrowth at 1, 2, and 4 weeks following olfactory nerve transection in the salamander.

Receptor neurons were greatly reduced in numbers at 1 week, and gradually returned to the normal percentage of intracellular penetrations by 4 weeks. They had a resting membrane potential between -30 and $-50 \mathrm{mV}$ and high input resistance, 100 to 600 megohms, characteristically seen in normal epithelium. However, at 1 week, the receptor neurons were able to generate only a single spike in response to injected current, and did not re-acquire their ability to respond repetitively until 4 weeks. Cells with the properties of immature receptor neurons (resting membrane potential between -30 and $-50 \mathrm{mV}$ and high input resistance, 100 to 600 megohms, but unable to generate spikes) increased significantly in number in the post-transection period. This correlates with the burst of mitotic activity giving rise to new receptor neurons after nerve transection. Supporting cells changed their properties in the aftermath of transection. One type (A) showed a decrease in resting membrane potential and a small increase in input resistance. A second type (B) showed a very large increase in input resistance. These results imply that the degenerating receptor neurons transmit a signal that leads to changes in the functional properties of the glial-like supporting cells. These may involve changes in the membrane properties or in electrical coupling between cells.
\end{abstract}

Our knowledge about the changes in physiological properties associated with degeneration and regeneration in the nervous system is limited (Pettigrew and Windle, 1976; Selzer, 1978; Wood and Cohen, 1979). The olfactory epithelium serves as a unique model to study these changes because of its ability to generate new receptor neurons throughout adult life (Graziadei, 1973). After olfactory nerve transection, there is virtually a complete degeneration and recovery of the receptor neuron population (Graziadei and Monti Graziadei, 1979; Simmons and Getchell, 1981a, 1981b), and receptor axons re-establish their synaptic connections with the olfactory bulb (Graziadei and Monti Graziadei, 1978; Simmons and Getchell, 1981b). The ability to regenerate new receptor neurons is possible because of the presence of stem cells that normally differentiate into receptor neurons in the adult.

We have examined with intracellular recordings the electro-

${ }^{1}$ This work was supported by Research Grants NS-07609 and NS10174 of the National Institute for Neurological and Communicative Disorders and Stroke. We thank Arthur Belanger for computer programming and Alfred Mueller for secretarial assistance. We are also grateful to Drs. Thane Benson, Ellen Lewis, and Patricia Pedersen for helpful suggestions concerning the histological procedures and Dr. John S. Kauer for valuable discussions.

${ }^{2}$ On leave of absence from Department of Biochemistry, Arrhenius Laboratory, University of Stockholm, S-106 91 Stockholm, Sweden. physiological characteristics of cells in the olfactory epithelium after olfactory nerve transection using an in vitro preparation of the salamander. Transection induced a decrease in numbers of mature receptor neurons, with loss of ability to generate repetitive spikes. There was an associated increase in presumed immature receptor neurons. In addition, significant changes were found in the glial-like membrane properties of neighboring supporting cells. The effects of nerve transection on the physiological properties of receptor neurons have interesting parallels with the properties of chromatolytic motoneurons (Eccles et al., 1958; Kuno and Llinas, 1970; Gustafsson, 1979; Heyer and Llinas, 1977) and lamprey spinal neurons (Yin et al., 1981). The electrical properties of the supporting cells are extremely sensitive indicators of the neuronal changes, implying interactions between the degenerating and newly generated neurons and the supporting cells.

\section{Materials and Methods}

Olfactory nerve transections were made in three groups of tiger salamanders (land phase), Ambystoma tigrinum. The animal was cooled and immobilized on ice and subcutaneous injections of xylocaine were made between the eyes where surgery was to be performed. The surgical area was cleansed with $70 \%$ alcohol. A flap of skin was reflected and the underlying bone was removed, exposing the rostral ends of the olfactory bulbs. The dura overlying the bulb was gently grasped by fine forceps and pulled back to reveal the olfactory nerve as it entered the bulb after emerging from the cribriform plate. Using ultrafine scissors under a dissecting microscope, the olfactory nerve was cut bilaterally. 
A small piece of Gelfoam was placed over the transection site to control hemorrhage. The bone and flap of skin were replaced and the surgical area was again cleansed with $70 \%$ alcohol. These procedures were similar to those used by Simmons and Getchell (1981a). The animals were kept in plastic boxes and cleaned at least every other day.

After 1 week, 2 weeks, or 4 weeks, animals were sacrificed and their dorsal epithelia were removed as described in the previous paper (Masukawa et al., 1984) for intracellular recording. The completeness of transection was verified by inspection under the dissecting microscope during removal of the epithelium for recording, and in some cases by histological preparations of serial sections through the rostral portions of the olfactory bulb. After the recordings, several epithelia at each time period were prepared for histological examination. This showed changes in the histology of the epithelium produced by the transection which were essentially identical to those described by Simmons and Getchell (1981a).

Intracellular electrical recordings were made from these epithelia as described in the previous paper (Masukawa et al., 1984). Changes in the electrical properties as examined in normal epithelial cells were determined in cells after the nerve transections. Recordings were made in the central region of the dorsal epithelial tissue.

Methods for acquiring and analyzing the electrophysiological data have been described in the preceding paper (Masukawa et al., 1984).

\section{Results}

Intracellular recordings were obtained from a total of 138 cells. These cells could all be classified according to the same physiological criteria for supporting cells, mature receptor neurons, and nonspiking receptor neurons as used in our previous study of the normal epithelium (with the addition of one subcategory for supporting cells) (Masukawa et al., 1984). We have therefore used the correlations with dye injections of supporting cells and mature receptor neurons in the previous study of the normal epithelium as a basis for their identification in this study. We have seen no evidence for other types of properties suggestive of recordings from other epithelial components such as cells of Bowman's glands. We will summarize the data obtained at each time period following nerve transection.

One week post-transection. One week after nerve transection, histological examination showed a thin and disrupted olfactory epithelium (cf. Simmons and Getchell, 1981a). Correlated with this, cell recordings were found over a more limited depth. The three cell types described in the normal epithelium (Masukawa et al., 1984) were present but in altered proportions (Table I). The major cell type seen was the supporting cell which had similar electrical properties as in normal epithelium (see Fig. 1 and Table I). The resting membrane potentials of the supporting cells 1 week after nerve transection were significantly lower than normal. The resting input resistances of most of the supporting cells, which we designated as type A, were significantly higher than normal. The membrane time constants calculated from the charging transients were within the range of values found for supporting cells in the normal epithelium (Masukawa et al., 1984).

In addition to the type $A$ supporting cell, another type of supporting cell was encountered in significant numbers (see Table 1). This will be designated a type B supporting cell because it shared the same high resting membrane potential as the supporting cell in normal epithelium, but instead of a low input resistance, the resistance was on the average 143 megohms (Fig. 2 and Table I), significantly higher than the type A supporting cell. As in type A cells, no action potentials could be generated.

The charging phase of the hyperpolarizing response of the type B supporting cell could be described by a single exponential function (which can be seen plotted in Fig. 2). Because of the relatively high input resistance, relatively small injected currents were needed to produce changes in membrane potential. In our best studied example, the depolarizing response to a current step displayed slight delayed rectification (large arrow); this had a latency (cf. inset, Fig. 2) of 15 to $20 \mathrm{msec}$ (from the small arrow). The membrane time constants calculated for the type B cells were 8 to $11 \mathrm{msec}$ (see Fig. 3 ). This is significantly longer than the values for type A supporting cells after transection and in normal epithelia (1 to 2 msec; see Masukawa et al., 1984). The longer time constant correlates with the higher input resistance in type B cells (see "Discussion").

Mature receptor neurons, with the ability to generate spikes in response to injected current, were relatively infrequent at this time period ( $9 \%$, see Table I). This reduced number compared with the normal epithelium is compatible with degeneration of the axotomized receptors (see "Discussion"). These mature receptor neurons identified electrophysiologically may be cells that had not completely degenerated or whose axons had not grown to the point of transection. The resting membrane potentials and input resistances of the receptor neurons were similar to those from the normal epithelium. An important difference between receptor neurons in the normal epithelium and 1 week post-transection was that only one action potential could be generated in response to a depolarizing current pulse, even at high intensity (Fig. 4). The action potential was followed by an afterhyperpolarization, as in the normal epithelium (Fig. 4). During the afterhyperpolarization immediately following the spike, the cell membrane was outwardly rectifying. The duration of this deflection was approximately $60 \mathrm{msec}$ following the spike. Histological examination of serial sections showed that the thickness of the epithelium at this time period was approximately half that in normal epithelium, which is comparable to the previous results of Simmons and Getchell (1981a, 1981b) in the salamander.

The occurrence of the nonspiking receptor neuron type was dramatically increased after transection. At this time period, the proportion of nonspiking receptor neurons was increased from $9 \%$ in normal tissue to its maximum after nerve transection of $19 \%$ (see Table I). The average resting membrane potential of these cells tended to be lower (mean of $-38 \mathrm{mV}$ compared to $-49 \mathrm{mV}$ in the normal epithelium), and the input resistance tended to be higher (from 156 to 289 megohms). Because of the scatter, these values were not statistically significant. Immature receptor neurons in normal epithelium showed outward rectification (Masukawa et al., 1984), and this property was also seen in this type of cell at the period following nerve transection.

Two weeks post-transection. The findings at 2 weeks posttransection indicated distinctive changes taking place in each of the specific cell populations. The dominant cell type continued to be the type A supporting cell. This was distinguishable by the same properties of resting membrane potential, input resistance, and membrane time constant as in the normal epithelium (see Table I). Type B supporting cells were encountered at their peak frequency in the post-transection period (see Table I). The input resistance was even higher than at 1 week. The range of values was similar to that of receptor neurons, but these Type B cells could be distinguished from receptor neurons by their combination of high resting membrane potential and lack of spike response to injected current. The larger membrane time constant and rectification with large currents that characterized these cells at one week post-transection were also seen at 2 weeks.

The receptor neurons penetrated during this period were capable of action potential generation, although they were still able to generate only one action potential in response to a current pulse (Fig. 5). In some cases, as in Figure 5, small spikelike potentials were seen in the response to higher current intensities. The discharge frequencies of the small potentials in Figure 5 are approximately 45 and $35 \mathrm{~Hz}$. In other respects, the receptor neurons were similar to those seen after 1 week, 
TABLE I

Electrical properties of four different cell types from the olfactory epithelium of the tiger salamander 1, 2, and 4 weeks after olfactory nerve transection

Values for normal epithelium are shown in parentheses under the values for 1 week.

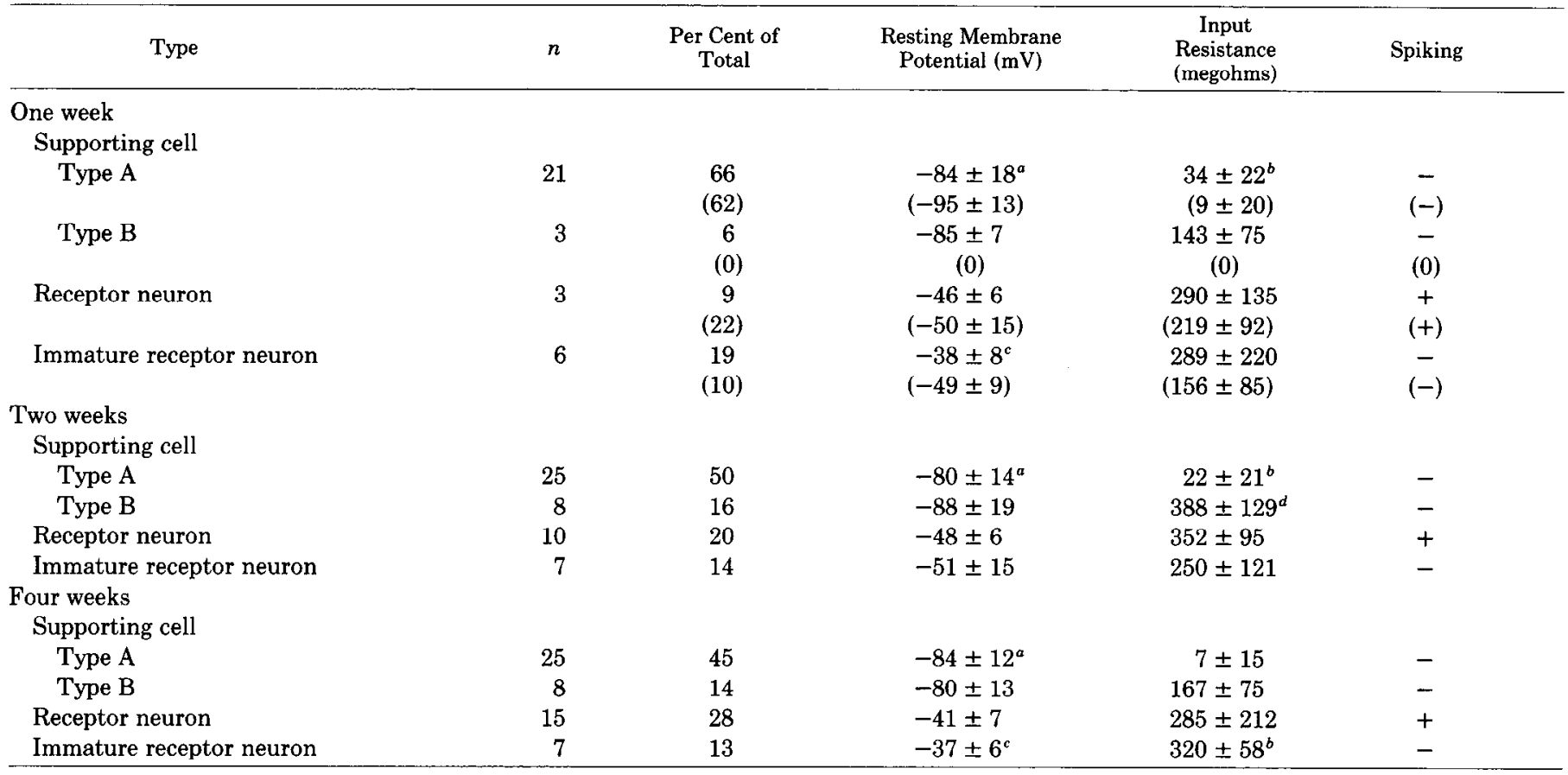

${ }^{a} p=0.01$ compared to the values for control epithelium.

${ }^{b} p=0.001$ compared to the values for control epithelium.

${ }^{c} p=0.05$ compared to the values for control epithelium.

${ }^{d} p=0.05$ compared to the values for 1 week.
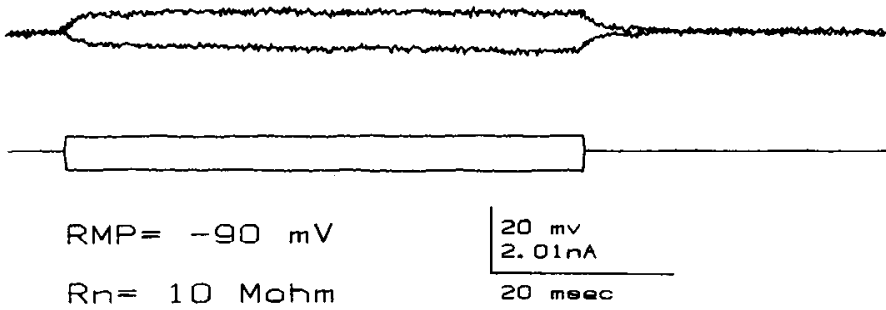

Figure 1. Electrical responses of a type A supporting cell in an olfactory epithelium 1 week after nerve transection. This cell type was indistinguishable from the supporting cells in normal epithelium. $R M P$, resting membrane potential; $R n$, input resistance.

except for a moderate increase in the input resistance, as seen in Table I. The increase in numbers of receptor neurons capable of generating action potentials may be related to the generation of new mature receptor neurons (see "Discussion").

At this time point, the resting membrane potential of the nonspiking receptor cell type was not significantly different from that in the normal epithelium (see Table I). The input resistances were slightly, but not significantly, higher (Table I). Rectification to injected current was present, as in cells of this type in normal cells and 1 week post-transection (see above).

Four weeks post-transection. Four weeks after nerve transection, histological examination showed that the cellular composition of the epithelium was similar to normal and the thickness had recovered to approximately $75 \%$ that of a normal epithelium (for normal values, see Simmons and Getchell, 1981a, 1981b; Masukawa et al., 1984). Correlated with this was a continued increase in the relative numbers of mature receptor neurons encountered in the recordings ( $28 \%$ of the cells pene-

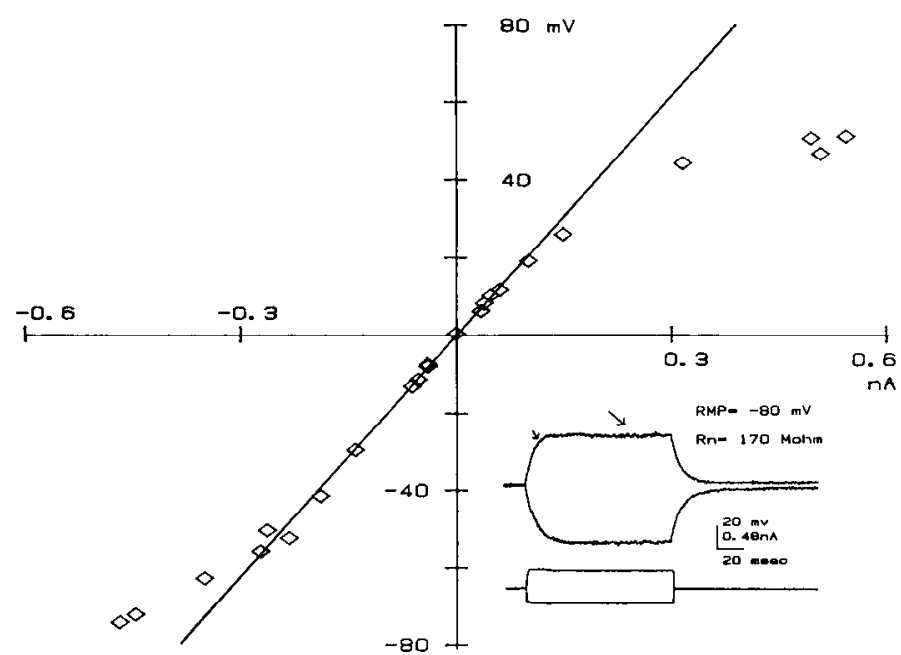

Figure 2. Electrical properties of a type B supporting cell. The graph shows current-voltage relations from measurements of the plateau phase of the response to injected current (representative recording in inset). The slope resistance for this cell was estimated to be 170 megohms. In the inset, the lower traces show the current monitor of the intracellularly injected current. The upper traces show corresponding depolarizing (up) and hyperpolarizing (down) responses of this cell. Action potential generation was not present in this cell type.

trated); these displayed electrical properties similar to those of receptor neurons in normal epithelia (see Table I).

In the supporting cell population, the numbers of type A cells penetrated were at their lowest level, and the resting membrane potential was still lower than normal. However, the input resistances were in the normal range (see Table I). Analysis of 


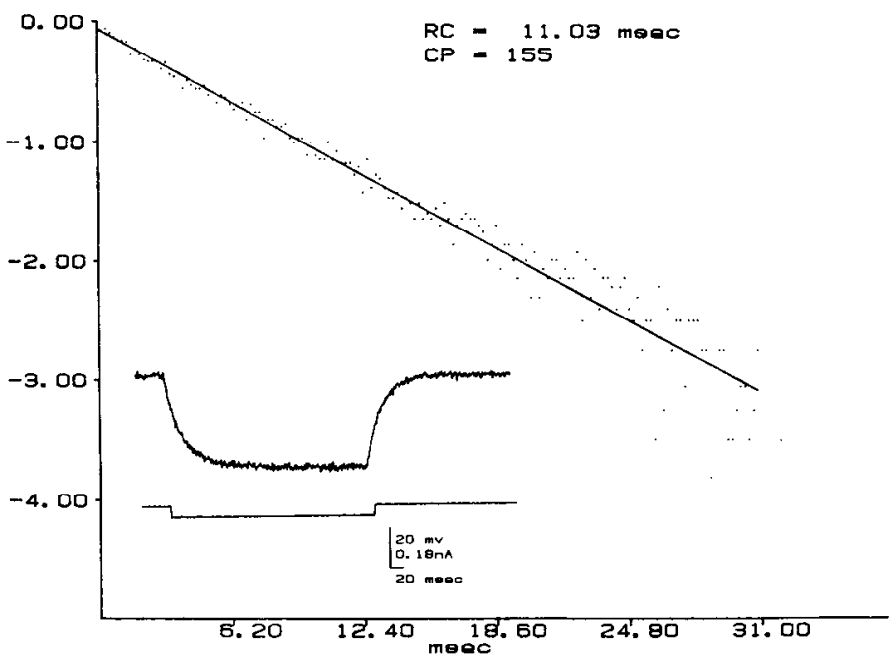

Figure 3. Analysis of the charging transient for a type B supporting cell. Representative response to a current pulse is shown in the inset. On the ordinate is the difference between the recorded and maximal (plateau) voltage response, normalized for the maximal response. On the abscissa is the time from the onset of response, in milliseconds. A nonlinear least squares regression fit of the data to a straight line was carried out by the computer. This gave the value of the membrane time constant $(R C)$ (see Rall, 1977). $C P$, number of data points.

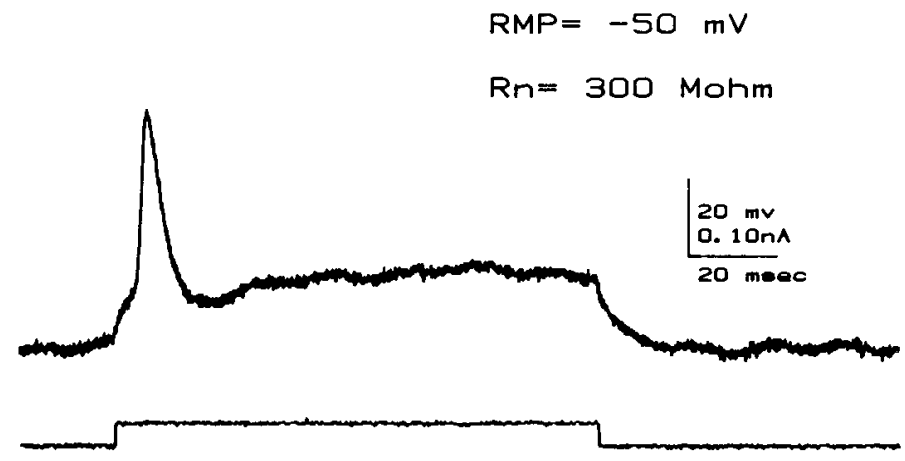

Figure 4. The response (top trace) of a presumed receptor neuron to a depolarizing current pulse (bottom trace) 1 week after olfactory nerve transection. Only a single action potential could be generated in response to this current pulse. No further action potentials could be evoked by greater current intensities. Note the afterhyperpolarization following the action potential.
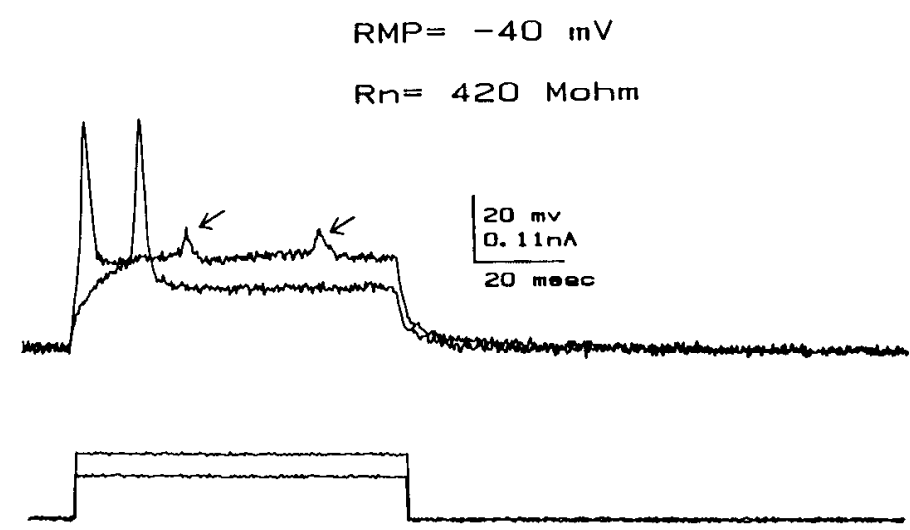

Figure 5. Electrical responses of a presumed receptor neuron in the olfactory epithelium 2 weeks after nerve transection. The upper pair of traces shows the voltage responses; the bottom pair shows the corresponding current pulses. Receptor neurons during this period either responded to a depolarizing current with one action potential or with one action potential followed by small bumps (indicated by arrows). the response to injected current showed a brief membrane time constant and an absence of rectification, similar to the properties in the normal epithelium.

The type B supporting cell was still present in a relatively high proportion. The resting membrane potentials remained at approximately the same level as at briefer post-transection times, but the input resistances had decreased from their peak at 2 weeks. The membrane time constant was still relatively long, and rectification was still present.

Mature receptor neurons were relatively easy to encounter at this time period. Their resting membrane potential and input resistance were in the normal range (see Table I), as was the membrane time constant. The most dramatic difference from 1 and 2 weeks was the return of the ability to generate a repetitive impulse discharge to depolarizing current. A typical example is shown in Figure 6, in which the response to three current intensities are superimposed. Note the large first spikes, and the reduction in amplitudes of the succeeding spikes, especially at higher current intensities. Note also the large spike afterhyperpolarizations, all characteristic of healthy recordings in normal epithelia.

The proportion of the nonspiking receptor neuron type continued to decline toward normal. The resting membrane potentials tended to be lower, and the input resistances significantly higher, than normal (see Table I), a situation which also was found at 1 week. Analysis of the membrane time constants gave values in the normal range of approximately $20 \mathrm{msec}$. The cells also showed membrane rectification, as illustrated in Figure 7. It can be seen in this typical example that the rectification took place with depolarizing currents, with outward rectification appearing with small amounts of current (approximately $0.1 \mathrm{nA}$ ).

\section{Discussion}

These are the first intracellular recordings of physiological changes in the main olfactory epithelial cell populations after olfactory nerve transection.

Our categorization of cell types in the normal epithelium has held throughout the post-transection period, and has been highly correlated with the cellular changes that have been described for the degenerating and regenerating olfactory epithelium by Graziadei and Monti Graziadei (1979) and with

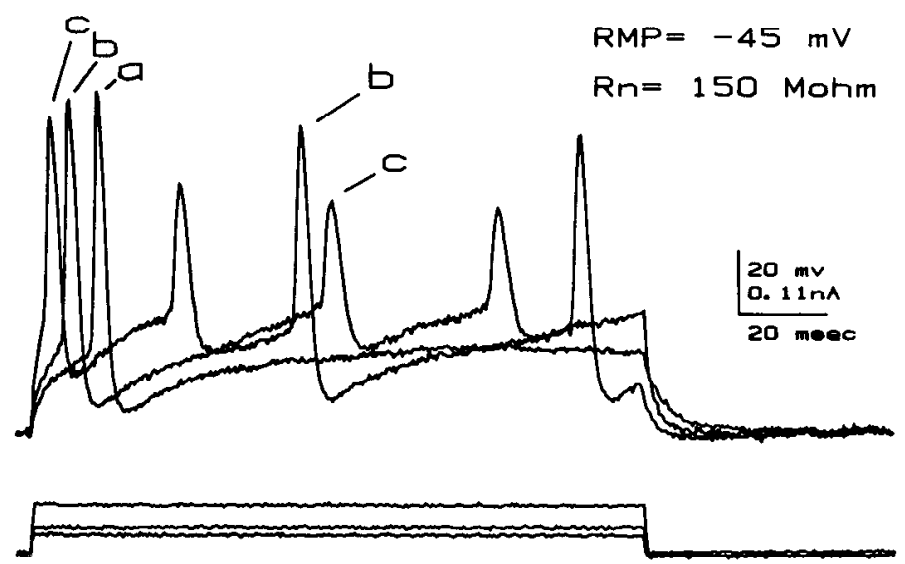

Figure 6. Four weeks after nerve transection, presumed receptor neurons showed action potential responses similar to those seen in normal olfactory epithelium. $a$, at a just threshold intensity of depolarizing current a single action potential was generated. $b$, at an intermediate current intensity, repetitive, slightly unattenuated, action potentials were generated. $c$, at higher current intensities, the subsequent action potentials were attenuated significantly. The top traces show the voltage responses; the bottom traces show the corresponding current pulses. 


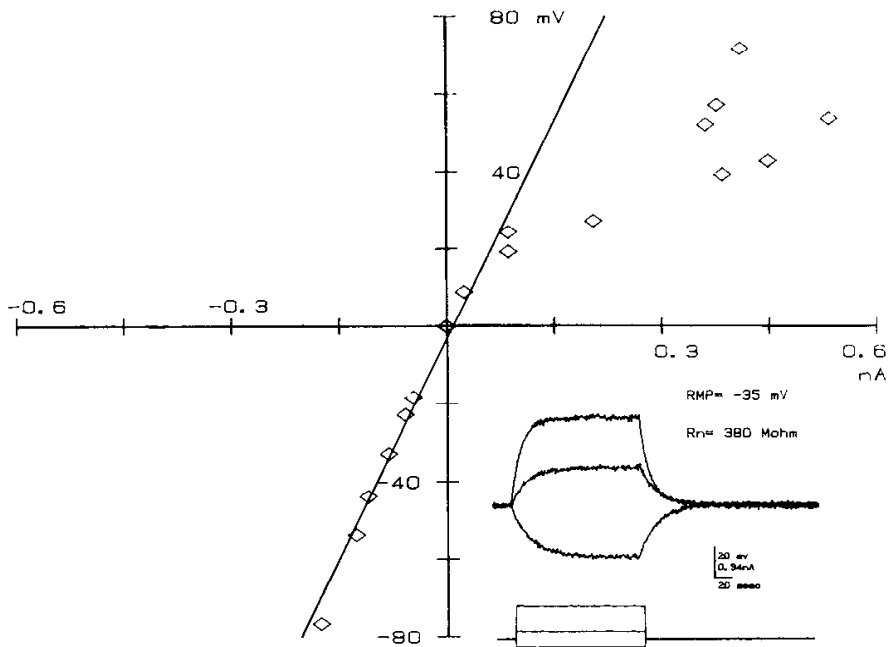

Figure 7. Current-voltage relations for a nonspiking presumed mature receptor neuron. Representative responses to current pulses in this cell are shown in the inset. The current-voltage relation was linear for hyperpolarizing currents, but there was a significant deviation from linearity with depolarizing currents above $0.1 \mathrm{nA}$. This cell did not generate action potentials to depolarizing current regardless of the amount of depolarization.

changes in extracellular unit recordings of spiking in receptor neurons by Simmons and Getchell (1981a, 1981b).

Changes in receptor neurons. Massive degeneration of receptor neurons occurs in the first week after transection. Morphological studies and extracellular unit recordings (Graziadei and Monti Graziadei, 1979; Simmons and Getchell, 1981a, 1981b) indicated immediate decrease in the epithelial mass and loss of spontaneous unit activity in presumed receptor neurons. Our data corroborate these previous findings in that the population of penetrable neurons is very low $(9 \%)$ by 1 week post-nerve transection, as opposed to $22 \%$ in normal epithelium. The receptor neurons have lost their capacity to generate repetitive action potentials. This correlates with loss of extracellular unit responses up to 10 days after nerve transection (Simmons and Getchell 1981a, 1981b).

The nonspiking, presumably immature receptor neuron populations increased dramatically, as would be expected from a synchronized differentiation of basal cells to replace degenerated receptor neurons (Graziadei and Monti Graziadei, 1978). Their input resistances tended to be higher than in normal cpithelia. The membrane time constants also varied over a larger range than normal. These findings suggest that, in addition to larger numbers, a more diverse population of nonspiking cells may be present after nerve transection. It is likely that within this population there may be cells at different stages of differentiation, from basal cells progressing to full cell maturity with axon differentiation and establishment of synaptic connections in the olfactory glomeruli. The factors that trigger this increase in cellular differentiation after nerve transection are of great interest, and will require further investigation.

Up to 4 weeks post-nerve transection, there is a shift back to a larger percentage of mature receptor neurons and a decrease in the number of nonspiking receptor neurons. In fact there seemed to be a rebound in the relative numbers of receptor neurons observed relative to the supporting type cells. Together with the increase in the relative numbers, the receptor neurons regained the ability to generate repetitive action potentials. These changes combine to restore the functional connection between the epithelium and olfactory bulb.

The recovery of the receptor cell population documented here is in agreement with the extracellular unit recordings of Simmons and Getchell (1981a). They observed return of normal unitary activity between days 25 and 45 after nerve transection. They also found a return to the normal epithelial thickness, whereas Graziadei and Monti Graziadei (1979) reported that the epithelium does not fully return, in agreement with our findings. However, we did not follow the epithelial recovery beyond 4 weeks to determine whether full recovery could be attained.

Changes in supporting cells. The other class of cell within the olfactory epithelium, the supporting cell, also showed dramatic changes. We suggest that the increased input resistance of the supporting cells we have designated as type B could be due either to a decrease in ionic conductance channels in the membrane or to an uncoupling of electrical junctions between these cells. A rearrangement of intercellular structures such as gap junctions could occur due to the degeneration of receptor neuron dendrites after nerve transection. The dendrite of a receptor neuron is a long process, 50 to $100 \mu \mathrm{m}$ in length and 1 to $2 \mu \mathrm{m}$ in diameter, that passes between the supporting cells. The olfactory vesicle, at the tip of the dendrite, protrudes past the tight junctional complex connecting the apices of the supporting cells. Gap junctions that indicate electrical communication have been observed by Kerjaschki and Horander (1976), and it may be hypothesized that some of these junctions are broken during olfactory receptor neuron degeneration and regeneration. It is interesting to note in this regard that the supporting cells of the olfactory epithelium have been compared to glial cells (Okano and Takagi, 1974; Getchell, 1977; Masukawa et al., 1984). In response to injury within the central nervous system, glial cells also lose their gap junctional connections (Somjen, 1975; Connors et al., 1984).

The appearance of the type B supporting cell was correlated with nerve transection. The sum of the two types of supporting cells encountered was approximately equal during the three time periods after nerve transection and in normal epithelium. This suggests that we were not recording from a new population of cells, but from cells of the same population which had changed their electrical characteristics. In addition, Graziadei and Monti Graziadei (1979), in studies using $\left[{ }^{3} \mathrm{H}\right]$ thymidine, reported that the supporting cell population was a static one which did not turn over. Among other cell types macrophages are present in epithelia after nerve transection. However, none of the cell types had the electrical characteristics of macrophages as described by Gallin and Gallin (1977) and more recently by McCann et al. (1983).

Relations to previous studies of degeneration and regeneration. As far as is known, there is no other vertebrate neuronal type which undergoes complete degeneration and de novo generation in response to transection of its axon (Grafstein and $\mathrm{Mc}$ Quarrie, 1978). The closest comparison is the chromatolytic degeneration and regeneration that neurons characteristically undergo after injury of their axons. Chromatolysis involves changes in RNA and protein synthesis, and disturbance of inorganic ion balances; depending on severity, the neuron either dies, or survives and attempts to send out a new axon (Grafstein and McQuarrie, 1978). The electrophysiological properties associated with chromatolysis have been best analyzed in the motoneuron (Eccles et al., 1958; Kuno and Llinas, 1970). According to Eccles et al. (1958), electrical properties such as the resting membrane potential, action potential and its afterpotential, input resistance, and membrane time constant are not changed during chromatolysis. However, a striking finding is the appearance of small spikes in intracellular recordings from the cell body; it is believed that these represent action potentials generated in the dendrites. The dendritic membrane apparently acquires excitable sites, implying that regenerative conductance channels (i.e., $\mathrm{Na}$ ) are inserted into the membrane. There are few other comparable electrophysiological studies (see Yin et al., 1981; Roederer and Cohen, 1983). 
In our results, the mature neuron cell type continued to show the same resting membrane potential, input resistance, initial action potential response, and membrane time constant as in the normal epithelium. However, it lacked the normal capacity to generate repetitive impulses. Thus, as in the chromatolytic motoneurons, the property most sensitive to nerve transection was related to impulse generation. At 2 weeks post-transection, the small repetitive potentials were seen. These have some similarity to the small dendritic spikes that are characteristic of chromatolytic motoneurons (Eccles et al., 1958; Kuno and Llinas, 1970). Further work will be necessary to determine whether the receptor neurons at these time intervals are in the process of degeneration or generation.

There is general agreement that glia play a critical role in determining the extent of axonal regeneration. Although there are considerable data on the anatomy of glial cells and their relation to regenerating nerves, and considerable interest in glia as sources of trophic factors (cf., Bunge, 1980), very little is known of changes in the electrophysiological properties of glial cells in the vicinity of chromatolytic and regenerating neurons.

As far as we can determine, the present study reports the first intracellular recordings from glial-like (supporting) cells in the vicinity of neurons after axonal transection. From this perspective, the most interesting aspect of these results is that the electrophysiological properties of supporting cells are extremely sensitive indicators of the effects of the axonal transection of the neighboring neurons. Basic properties, such as resting membrane potential and input resistance, were significantly shifted, though not out of the range characteristic of these cells. In addition, a new subcategory of glial-like cells emerged; as we have discussed above, this may reflect changes in membrane conductance or gap junctions. These results imply the passage of a signal from the affected neurons to the supporting cells. Degenerating and regenerating neurons may interact with surrounding glial cells by similar mechanisms (Somjen, 1975, 1981). Further work in the olfactory epithelium needs to be directed to shorter intervals following transection, to attempt to characterize the onset and nature of these neuronal-glial interactions.

\section{References}

Bunge, R. P. (1980) Some observations on the role of the Schwann cell in peripheral nerve regeneration. In Nerve Repair and Regeneration, D. L. Jewett, ed., pp. 58-64, C. V. Mosby, St. Louis.

Connors, B. W., Benardo, L. S., and Prince, D. A. (1984). Carbon dioxide sensitivity of dye coupling among glia and neurons of the neocortex. J. Neurosci. 4: 1324-1330.

Eccles, J. C., Libet, B., and Young, R. R. (1958) The behaviour of chromatolysed motorneurones studied by intracellular recordings. $\mathrm{J}$. Physiol. 143: 11-40.

Gallin, E. K., and Gallin, J. I. (1977) Interaction of chemotactic factors with human macrophages. Induction of transmembrane potential changes. J. Cell Biol. 75: 277-289.

Getchell, T. V. (1977) Analysis of intracellular recordings from salamander olfactory epithelium. Brain Res. 123: 275-286.
Grafstein, B., and McQuarrie, I. G. (1978) Role of the nerve cell body in axonal regeneration. In Neuronal Plasticity, C. W. Cotman, ed., pp. 155-195, Raven Press, New York.

Graziadei, P. P. C. (1973) Cell dynamics in the olfactory mucosa. Tissue Cell 5: 113-131.

Graziadei, P. P. C., and Monti Graziadei, G. A. (1978) Continuous nerve cell renewal in the olfactory system. In Handbook of Sensory Physiology. Vol. IX: Development of Sensory Systems, M. Jacobson, ed., pp. 55-83, Springer Verlag, New York.

Graziadei, P. P. C., and Monti Graziadei, G. A. (1979) Neurogenesis and neuron regeneration in the olfactory system of mammals. I. Morphological aspects of differentiation and structural organization of the olfactory sensory neurons. J. Neurocytol. 8: 117.

Gustafsson, B. (1979) Changes in motoneurone electrical properties following axotomy. J. Physiol. 293: 197-215.

Heyer, C. B., and Llinas, R. (1977) Control of rhythmic firing in nurmal and axotomized cat spinal motoneurones. J. Neurophysiol. 40: 480488.

Kerjaschki, D., and Horander, H. (1976) The development of mouse olfactory vesicles and their cell contacts: a freeze-etching study. J. Ultrastruct. Res. 54: 420-444.

Kuno, M., and Llinas, R. (1970) Enhancement of synaptic transmission by dendritic potentials in chromatolysed motorneurones of the cat. J. Physiol. 210: 807-821.

Masukawa, L. M., Hedlund, B., and Shepherd, G. M. (1984) Electrophysiological properties of identified cells in the in vitro olfactory epithelium of the tiger salamander. J. Neuroscience 5: 128-135.

McCann, F. V., Cole, J. J., Guyre, P. M., and Russel, J. A. G. (1983) Action potentials in macrophages derived from human monocytes. Science 219: 991-993.

Okano, M., and Takagi, S. F. (1974) Secretion and electrogenesis of the supporting cell in the olfactory epithelium. J. Physiol. 242: 353370.

Pettigrew, R. K., and Windle, W. F. (1976) Factors in recovery from spinal cord injury. Exp. Neurol. 53: 815-829.

Rall, W. (1977) Core conductor theory and cable properties of neurons. In Handbook of Physiology (E. R. Kandel, ed.), Sect. 1, The Nervous System, Vol. 1, Cellular Biology of Neurons, pp. 39-97, The American Physiological Society, Bethesda.

Roederer, E., and Cohen, M. J. (1983) Regeneration of identified central neuron in the cricket. I. Control of sprouting from the dendrites, soma and axon. J. Neurosci. 3: 1848-1859.

Selzer, M. E. (1978) Mechanism of functional recovery and regeneration after spinal cord transection in larval sea lamprey. J. Physiol. 277: 395-407.

Simmons, P. A., and Getchell, T. V. (1981a) Neurogenesis in olfactory epithelium: loss and recovery of transepithelial voltage transients following olfactory nerve section. J. Neurophysiol. 45: 516-528.

Simmons, P. A., and Getchell, T. V. (1981b) Physiological activity of newly differentiated olfactory receptor neurons correlated with morphological recovery from olfactory nerve section in the salamander. J. Neurophysiol. 45: 529-549.

Somjen, G. G. (1975) Electrophysiology of neuroglia. Annu. Rev. Physiol. 37: $163-170$.

Somjen, G. (1981) Physiology of glial cells. In Physiology of NonExcitable Cells (J. Salanki, ed.), pp. 23-43, Academiai Kiado, Budapest.

Wood, M. R., and Cohen, M. J. (1979) Synaptic regeneration in identified neurons of the lamprey spinal cord. Science 206: 344-347.

Yin, H. S., Wellerstein, K. K., and Selzer, M. E. (1981) Effects of axotomy on lamprey (Petromyzon marinus) spinal neurons. Exp. Neurol. 73: 750-761. 